\title{
Enhanced radiation effect on SMCC7721 cells through endoplasmic reticulum stress induced by C225-GNPs in vitro and in vivo
}

\author{
CHUANDONG ZHU ${ }^{1 *}$, LIXUE WANG $^{2 *}$, YANG CAI $^{3}$, GUOXIANG WANG $^{4}$, \\ HANFENG XU ${ }^{1}$, YUAN WAN ${ }^{5}$ and QIN ZHENG ${ }^{1,2}$
}

\begin{abstract}
Departments of ${ }^{1}$ Oncology and ${ }^{2}$ Oncological Radiotherapy, The Second Hospital of Nanjing Affiliated to Medical School of Southeast University, Nanjing, Jiangsu 210003; ${ }^{3}$ Department of Oncology, Xishan People's Hospital, Wuxi, Jiangsu 214011; ${ }^{4}$ Nanjing Zetect Bioscience Incorporated, Nanjing, Jiangsu 210061, P.R. China;

${ }^{5}$ Department of Biomedical Engineering, Pennsylvania State University, State College, PA 16801, USA
\end{abstract}

Received June 29, 2017; Accepted December 29, 2017

DOI: $10.3892 / 01.2018 .7864$

\begin{abstract}
The high atomic number of gold nanoparticles (GNPs) enables them to offer potential as practical and efficient radiosensitizing agents for cancer radiotherapy applications. In the present study, it was demonstrated that GNPs can significantly modulate the irradiation response of hepatocellular carcinoma (HCC) cells in vitro and in vivo, of which the underlying mechanisms were investigated. Cetuximab (C225) is a targeting agent, which binds to the extracellular domain of epidermal growth factor receptor (EGFR). Hepatocyte-targeting, EGFR-specific C225 was synthesized onto GNP surfaces (C225-GNPs) to increase the GNP targeting specificity. C225-GNPs was synthesized successfully and characterized. The cytotoxicity was tested using a Cell Counting Kit-8 assay and 50\% inhibition concentration of SMCC7721 cells was calculated. Cell uptake assay was detected using transmission electron microscopy. Radiosensitization was tested using a cell colony formation assay and cell cycle was detected using flow cytometry. The expression of a number of apoptotic proteins were tested by western blot analysis. Orthotropic SMCC7721 xenografts were used in order to verify its radiosensitizing effect. The results
\end{abstract}

Correspondence to: Dr Yuan Wan, Department of Biomedical Engineering, Pennsylvania State University, N261 Millennium Science Complex, Pollock Road, State College, PA 16801, USA

E-mail: yuw33@psu.edu

Dr Qin Zheng, Department of Oncology, The Second Hospital of Nanjing Affiliated to Medical School of Southeast University, 1-1 Zhongfu Road, Nanjing, Jiangsu 210003, P.R. China

E-mail: njzq83626472@sina.com

*Contributed equally

Key words: gold nanoparticle, SMCC7721 cell, cetuximab, radiosensitization, endothelial network stress revealed that a higher number of C225-GNPs were effectively uptaken by SMCC7721 cells and markedly enhanced cancer cell death. The sensitization mechanism of C225-GNPs was associated with the apoptotic gene signalling process activated by endoplasmic reticulum stress and the unfolded protein response in cancer cells. In orthotopic SMCC7721 xenografts, the C225-GNPs significantly enhanced the radiation-induced suppression of tumour growth. The results of the present study provided evidence that C225-GNPs are potent radiosensitizers with radiotherapeutic value for $\mathrm{HCC}$ with the overexpression of EGFR.

\section{Introduction}

Hepatocellular carcinoma (HCC) is one of the most life-threatening types of cancer in the world, with $>50,000$ new patients being diagnosed every year (1). The majority of patients with HCC are asymptomatic at the early stage and, due to delayed diagnosis numerous patients with HCC are unable to undergo radical resection or transplantation. Therefore, there is an urgent requirement to examine other potential therapeutics to enhance the outcome in patients with HCC. Radiation therapy (RT) is commonly used in patients with HCC who are unable to undergo resection or transplantation (2). With the progress of three-dimensional conformal RT and stereotactic body RT, RT has shown promising results for $\mathrm{HCC}$ in clinical trials (3). However, its effectiveness in larger tumours, particularly in HCC, is limited by radiosensitivity due to radiation resistance, and radiation-induced liver disease (RILD) also limits the efficiency of radiation therapy $(4,5)$. Therefore, an innovative approach to manage RILD and radiation resistance is likely to be of significant therapeutic benefit to patients with HCC and clinical trial treatments. The use of radiosensitizers is a reasonable method to enhance the radiosensitivity of $\mathrm{RT}$ for $\mathrm{HCC}$.

Among various radiosensitizers investigated for radiotherapeutic applications, gold nanoparticles (GNPs) have been investigated more extensively due to their high X-ray absorption coefficient, and their tuneable size, unique surface 
chemistry, electronic properties and low osmolality $(6,7)$. GNPs have unique physiochemical surface properties, which allow them to be coated with various antibodies, peptides, proteins, aptamers and other biomolecules, which facilitates specific targeting to cancer cells and increased GNP accumulation in the tumour, leading to an enhanced radiation effect. Using GNPs to enhance the dose of X-ray radiation absorbed by tumours has attracted increasing attention (8-10).

Specific delivery can be accomplished by conjugating GNPs to antibodies or ligands, which target overexpressed proteins on cancer cell surfaces (11). Cetuximab (C225), a targeting agent, is a chimeric human-murine monoclonal antibody, which binds to the extracellular domain of epidermal growth factor receptor (EGFR) (12). EGFR is an attractive target, which is overexpressed in a number of human malignancies, including HCC (13). It was hypothesized that EGFR-targeted GNPs may enhance the cytotoxic effects of radiation therapy, and concentrate the effect on targeted tumour cells. EGFR targeting has been achieved using several immunoconjugates, including C225 conjugated to GNPs, in several cancer cell lines and cancer models (14-16). C225-conjugated GNPs are highly stable in serum. However, few reports are available on the radiosensitivity of HCC treatment with antibody-functionalised GNPs, and the exact mechanism by which radiosensitization occurs remains to be elucidated. To investigate this, the present study synthesized GNPs coated with C225 (C225-GNPs) to investigate their radiosensitivity on an EGFR-overexpressing HCC cell line (SMCC7721). The results demonstrated that the $\mathrm{C} 225-\mathrm{GNPs}$ offer potential as radiosensitizers for $\mathrm{HCC}$ therapy.

\section{Materials and methods}

Cell culture. The SMCC7721 cells were cultured in RPMI 1640 medium (Gibco; Thermo Fisher Scientific, Inc., Waltham, MA, USA) supplemented with $10 \%$ heat-inactivated foetal calf serum (Gibco; Thermo Fisher Scientific, Inc.) and 1\% penicillin-streptomycin (Gibco; Thermo Fisher Scientific, Inc.) at $37^{\circ} \mathrm{C}$ under a humidified atmosphere containing $5 \% \mathrm{CO}_{2}$ and maintained in an exponential growth state. The cells were passaged and harvested once every 3 days using $0.25 \%$ trypsin.

Preparation and characterization of C225-GNPs. The synthesis of naked GNPs with a 20-nm diameter was accomplished using a sodium citrate reduction method. The preparation method has been described previously (17). The size of the GNPs was determined by transmission electron microscopy (TEM; JEM-100CX II; JEOL, Ltd., Tokyo, Japan) images. The method used for synthesizing the GNP-C225 conjugates was previously performed by El-Sayed et al (18). Briefly, a solution of GNPs $(50 \mu \mathrm{g} / \mathrm{ml})$ was diluted with HEPES solution ( $\mathrm{pH} 8.0)$. The C225 (500 $\mu \mathrm{l})$ was diluted to a final volume of $5 \mathrm{ml}$ with HEPES solution, and the mixture was added to $10 \mathrm{ml}$ of the GNP solution; the $15-\mathrm{ml}$ final volume solution was stirred vigorously at room temperature for $2 \mathrm{~h}$. The mixture was then centrifuged at $1,500 \times \mathrm{g}$ for $30 \mathrm{~min}$ at $4^{\circ} \mathrm{C}$ to separate the desired GNP-antibody from unconjugated antibody. The conjugates formed a loose pellet at the bottom of the centrifuge tube and were carefully collected. The pellet was then diluted in $10 \mathrm{ml} \mathrm{PBS}(\mathrm{pH} \mathrm{7.8)}$ ) and vortexed for $10 \mathrm{~min}$. The gold concentration of the conjugates was determined from the absorbance obtained by UV-visible spectrometry (Tianjin Gangdong Science and Technology Development Co., Ltd., Tianjin, China) absorbance at $500 \mathrm{~nm}$ (A500). The GNPs were characterized by TEM following drop-coating $100 \mu \mathrm{l}$ of the sample on a carbon-coated copper grid. Dynamic light scattering spectroscopy (DLS; HORIBA Jobin Yvon, Edison, NJ, USA) allowed for determination of the hydrodynamic diameter of colloidal particles and conjugates, which was the diameter of a sphere with the same Brownian motion as the analysed particle.

Determining the number of $C 225$ molecules bound to a GNP. The number of C225 molecules bound to GNP was calculated by ELISA (17). Briefly, $100 \mu \mathrm{l}$ of the standards sample was added to an ELISA plate according to its sequence, and $200 \mu 1 \mathrm{C} 225-\mathrm{GNP}$ solution was added to the same micropore. C225 solution $(10 \mu \mathrm{l}, 2 \mu \mathrm{g} / \mu \mathrm{l})$ was added to the microplate as a control. All the samples were disposed with $10 \mu \mathrm{g} / \mu \mathrm{l}$ horseradish peroxidase (HRP)-labelled goat anti-mouse-IgG (1:2,000; cat no. KGAA36; Nanjing KeyGen Biotech Co., Ltd., Nanjing, China) and incubated for $1 \mathrm{~h}$ at room temperature. The C225-GNP conjugates were centrifuged at $1,500 \mathrm{x} \mathrm{g}$ at $4^{\circ} \mathrm{C}$ for $15 \mathrm{~min}$ to remove the unconjugated HRP. Subsequently, tetramethyl benzidine was reacted with HRP for $15 \mathrm{~min}$, and $2 \mathrm{~mol} / \mathrm{l}$ sulphuric acid was added to terminate the reaction. The number of $\mathrm{C} 225$ antibodies bound to C225-GNPs was determined by UV-visible spectrometry at $450 \mathrm{~nm}$, which was compared with the standard curve of the HRP-anti-IgG/C225. The number of C225 antibodies bound per GNP was calculated from the total number of C225 antibodies in the solution divided by the total number of GNPs in the solution (19).

Nanoparticle cytotoxicity assay. Cell Counting Kit-8 (CCK8; Nanjing KeyGen Biotech Co., Ltd.) assays were used to determine the cytotoxicity of C225, GNPs and C225-GNPs. The assays were performed according to the manufacturer's protocol to assess cell viability. The cells were cultured at a density of $3 \times 10^{3}$ cells per well in flat-bottomed 96-well plates. The C225, GNPs and C225-GNPs were diluted to various concentrations in $1 \mathrm{X} \mathrm{PBS}(\mathrm{Ph} 7.4)$, and then added into the wells and incubated for $24 \mathrm{~h}$ at $37^{\circ} \mathrm{C}$, followed by exposure to $10 \mu \mathrm{lCCK} 8$, which was added to each well for $2 \mathrm{~h}$. The absorbance was measured at $490 \mathrm{~nm}$ using a microplate reader (DG3022; Bio-Rad Laboratories, Inc., Hercules, $\mathrm{CA}, \mathrm{USA})$ and the $50 \%$ inhibition concentration $\left(\mathrm{IC}_{50}\right)$ value was estimated.

Cell uptake assay. The SMCC7721 cells were treated with GNPs or C225-GNPs (the concentrations of GNPs and C225-GNPs was $1 / 5$ of the $\mathrm{IC}_{50}$ for $24 \mathrm{~h}$ ) and were centrifuged with $500 \mathrm{x} \mathrm{g}$ at $37^{\circ} \mathrm{C}$ for $10 \mathrm{~min}$ and fixed in $2.5 \%$ glutaraldehyde for $4 \mathrm{~h}$ at room temperature, followed by rinsing with PBS twice. The cells were then gradually dehydrated with 70 , 80 and $90 \%$ acetone solutions, and embedded in epoxy resin at $60^{\circ} \mathrm{C}$ for $48 \mathrm{~h}$. Ultra-thin sections $(70-100 \mathrm{~nm})$ were cut with an ultramicrotome and stained with $5 \%$ uranyl acetate in $50 \%$ ethanol, followed by $2 \%$ aqueous lead citrate. Finally, 
the ultra-thin sections were imaged by TEM at $200 \mathrm{KV}$. Flame atomic absorption spectroscopy (FAAS; SpectrAA 140; Agilent Technologies, Inc., Santa Clara, CA, USA) was used to measure the gold concentrations of the two groups. Briefly, the SMCC7721 cells were incubated with GNPs or C225-GNPs for $2 \mathrm{~h}$, the medium was removed and the cells were washed three times with PBS to remove excess nanoparticles. The cells were collected and gold concentrations in the samples were measured by FAAS. The number of GNPs within the cells was calculated according to the particle diameter.

Clonogenic assay. To assess clonogenic survival, the SMCC7721 cells were pretreated with C225, GNPs or C225-GNPs for $24 \mathrm{~h}$, following which the drugs were removed and the cells were exposed to $0,1,2,4,6$ or 8 Gy $\mathrm{X}$-ray radiation from a medical linear accelerator (Varan linear accelerator; Unique Medical Systems, Palo Alto, CA, USA) and incubated for 12 days at $37^{\circ} \mathrm{C}$. The visible colonies with $>50$ cells were counted and fixed with methanol followed by trypan blue staining. The cell survival curve was estimated according to a multitarget single-hit model: $\mathrm{y}=1-[1-\exp (-\mathrm{k} * \mathrm{x})]^{\wedge} \mathrm{N},(\mathrm{y}=$ probability of survival; $\mathrm{k}=\mathrm{a}$ dose that causes a mean of one hit per cell, $x=$ number of hits per cell, $\mathrm{N}=$ number of targets, and $\mathrm{D} 0=\mathrm{a}$ dose that causes a mean of one-hit per cell) was calculated. The sensitization enhancement ratio (SER) was determined by the ratio of radiation dose resulting in $50 \%$ survival of the cells.

Apoptotic assay. The cells were treated with GNPs, C225 or C225-GNPs for $24 \mathrm{~h}$ followed by X-ray irradiation (2 Gy). Apoptosis was detected in $5 \times 10^{5}$ cells washed with PBS by staining with $5 \mu \mathrm{l}$ Annexin V-APC and $5 \mu 1$ 7-AAD (Nanjing KeyGen Biotech Co., Ltd..). The stained cells were analysed using a flow cytometer.

Western blot analysis. The cells were treated with C225, GNPs or C225-GNPs for $24 \mathrm{~h}$ followed by X-ray irradiation (2 Gy). The cells were lysed in lysis buffer $20 \mathrm{mM}$ HEPES-NaOH (pH 7.4), 2 mM EGTA, 50 mM glycerophosphate, $1 \%$ Triton $\mathrm{X}-100,10 \%$ glycerol, $1 \mathrm{mM}$ PMSF, $10 \mu \mathrm{g} / \mathrm{ml}$ leupeptin, $10 \mu \mathrm{g} / \mathrm{ml}$ aprotinin and $10 \mu \mathrm{g} / \mathrm{ml}$ pepstatin]. The cells were lysed using RIPA buffer (cat no. P0013; Beyotime Institute of Biotechnology, Shanghai, China), protein lysates $(20 \mu \mathrm{g})$ were resolved using 10\% SDS-PAGE. Protein was quantified using a micro BCA kit (cat.no. 23235; Thermo Fisher Scientific, Inc.) according to the manufacturer's protocol and analyzed using an acrylamide gel and then transferred onto a nitrocellulose membrane. The membrane was probed with specific antibodies against B-cell lymphoma 2 (Bcl-2; 1:500; cat no. SAB1306605), Bcl-2-associated X protein (Bax; 1:500; cat no. SAB2108447), caspase-3 (1:500; cat no. C5737), glucose-regulated protein 78 (GRP78; 1:800; cat no. G9043), inositol-requiring enzyme (IRE1 $\alpha$; 1:800; cat no. I6785) and PRKR-like endoplasmic reticulum kinase (PERK; 1:800; cat no. P7704), all from Sigma; Merck Millipore (Darmstadt, Germany) diluted with TBST [10 mM Tris- $\mathrm{HCl}$ (pH 7.4), 0.1 M NaCl and 0.1\% Tween-20] containing $5 \%$ non-fat skim milk overnight at $4^{\circ} \mathrm{C}$. Following washing, the membranes were subsequently incubated with HRP-conjugated secondary antibodies (IgG; cat. no. KGAA36;
Nanjing KeyGen Biotech Co., Ltd.), followed by application of enhanced chemiluminescence kits. $\beta$-actin was used as an internal control.

Xenograft assay. Four-week-old specific pathogen-free athymic (T-cell deficient) nude mice were purchased from the Model Animal Research Center (Nanjing, China). For the generation of hepatic tumour models, single-cell suspensions $\left(2 \times 10^{6}\right.$ cells in $0.1 \mathrm{ml}$ HBSS $)$ were injected into the right subcutaneous armpit of each nude mouse. The mice were randomly distributed into four groups $(n=5)$ following tumour cell implantation. C225-GNPs or GNPs at a gold concentration of $220 \mu \mathrm{g} / \mathrm{ml}$ were injected into the tumour of each mouse or $20 \mathrm{mg} / \mathrm{kg}$ of $\mathrm{C} 225$. For X-ray irradiation, the mice were exposed to $2.5 \mathrm{~Gy}$ of X-rays operating at $6 \mathrm{MV}$ every 3 days. The total dose and dose rate for each mouse was $20 \mathrm{~Gy}$ and $1.23 \mathrm{~Gy} / \mathrm{min}$, respectively. Following X-ray irradiation, the mice were housed in micro-isolator cages until the time of sacrifice. The room temperature was maintained between 24 and $26^{\circ} \mathrm{C}$, and the relative humidity was maintained between 60 and $70 \%$. The institutional laboratory housing provided a 12-h light/dark cycle and nude mice were allowed ad libitum access to food and water. The tumours were measured every 3 days with callipers, and the diameters were recorded. Tumour volume was calculated by the formula $a^{2} b / 2$, where $a$ and $b$ are the two maximum diameters. The care and use of animals in the present study was approved by the Animal Laboratory of Southeast University (Nanjing, China) and the Use Committee, and conformed to international guidelines on the ethical use of animals. All efforts were made to minimize the number of experimental animals and their suffering.

Statistical analysis. The data are expressed as the mean \pm standard deviation. Significance was evaluated by one-way analysis of variance or Student's t-test, as appropriate. Statistical comparisons of slopes were made using the F-test. All statistical analysis was performed using GraphPad Prism 6 (GraphPad Software, Inc., La Jolla, CA, USA). P<0.05 was considered to indicate a statistically significant difference.

\section{Results}

Characterization of C225-GNPs. Following coating of the GNPs with C225, the nanoparticle diameters observed by TEM imaging ranged between 15 and $26 \mathrm{~nm}$ (mean diameter of $21.7 \mathrm{~nm})$, which were the same as the uncoated GNPs $(\sim 20.6 \mathrm{~nm})$. However, in contrast to the uncoated GNPs, C225-GNPs exhibited a thin white ring structure on the surface (Fig. 1A) when stained with $2 \%$ phosphotungstic acid. The average particle size produced was $24.5 \pm 0.9 \mathrm{~nm}$ for uncoated GNPs, and 41.1 $\pm 4.4 \mathrm{~nm}$ for C225-GNPs, as determined by DLS (Fig. 1B). The UV-Vis spectra (Fig. 1C) showed a marginal redshift in the particles, indicating C225 attachment to the surface of the GNPs.

Quantity of C225 conjugated to GNPs. Gradient dilutions of goat anti-mouse IgG coated with HRP were incubated with C225-GNPs, and the absorbance (OD) was measured when the substrate was added. The standard curve for HRP-anti-IgG/C225 was calculated following determining 
A
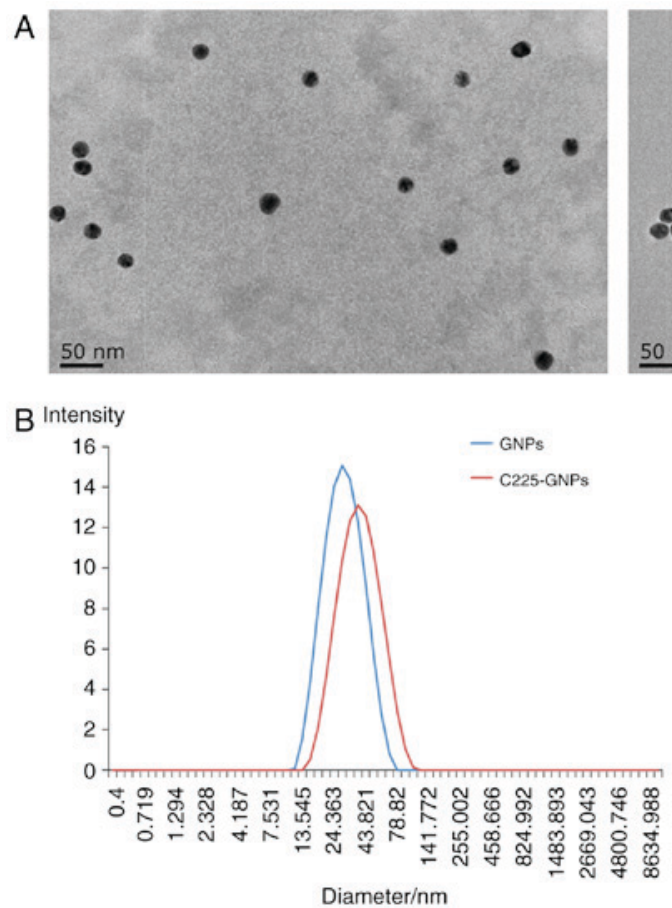

Diameter/nm
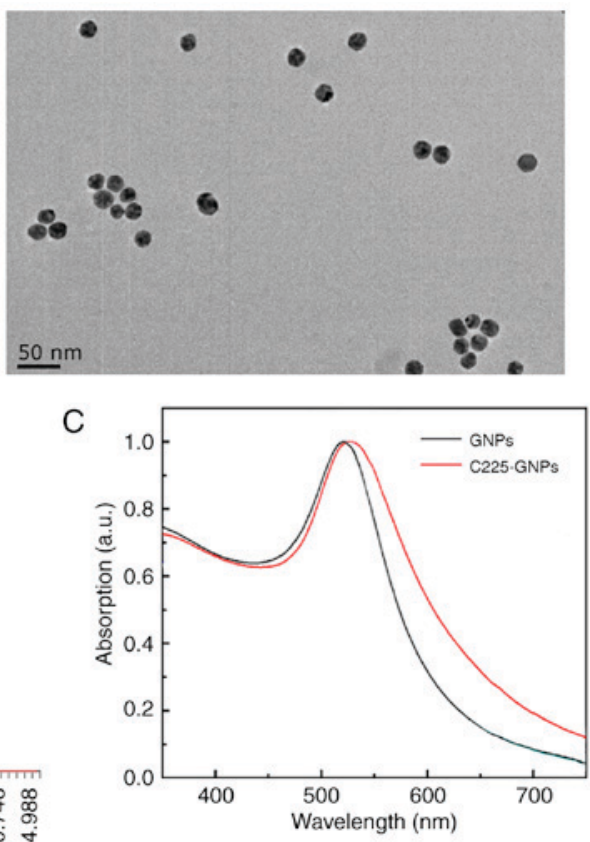

Figure 1. Characterization of nanoparticles. (A) Images of GNPs (left) and C225-GNPs (right) detected by transmission electron microscopy. (B) Size distribution of GNPs (blue) and C225-GNPs (red) measured by dynamic light scattering spectroscopy. (C) Absorption peak of GNPs (black) and C225-GNPs (red). GNPs, gold nanoparticles; C225, cetuximab.
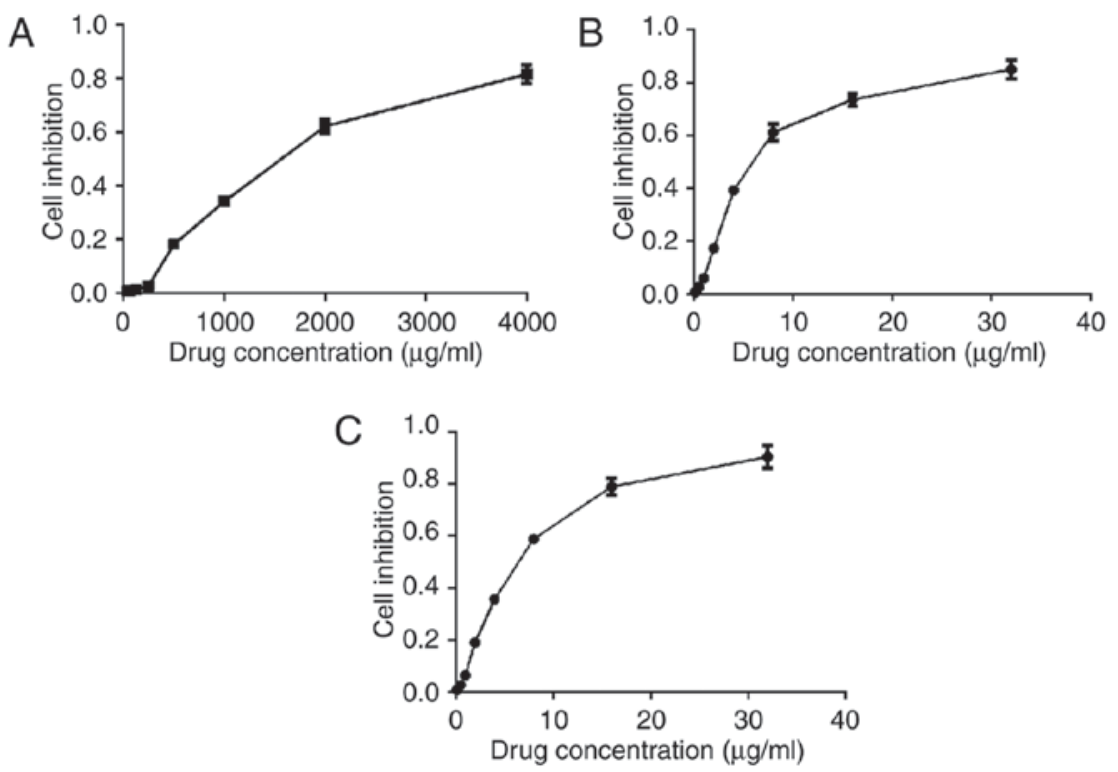

Figure 2. Cytotoxicity of C225, GNPs and C225-GNPs at various concentrations in SWCC7721 cells. A colorimetric Cell Counting Kit-8 assay was performed to measure the cytotoxicity according to the manufacturer's protocol. (A) C225; (B) GNPs; (C) C225-GNPs. GNPs, gold nanoparticles; C225, cetuximab.

the highest OD value, and the quantity of $\mathrm{C} 225$ in $200 \mu \mathrm{l}$ of C225-GNP solution was $2.83 \mu \mathrm{g}$; the number of $\mathrm{C} 225$ molecules $(\mathrm{A})=0.65 \times 10^{-6} /\left(152 \times 10^{3}\right) \times 6.02 \times 10^{23}$ (the molecular weight of $\mathrm{C} 225$ is $152 \mathrm{kDa}$ ). There was $10 \mu \mathrm{g}$ of gold nanoparticles in $200 \mu 1$ of C225-GNPs solution $(50 \mu \mathrm{g} / \mathrm{ml})$, therefore, the number of gold atoms $(B)=10 \times 10^{-6} / 196.966=5.08 \times 10^{-8}$ mol=50.8 nmol. The number of gold atoms $\left(\mathrm{N}_{\mathrm{A}}\right)$ contained in each gold nanometre wascalculated using the following formula: $\mathrm{N}_{\mathrm{A}}=\left(59 \mathrm{~nm}^{-3}\right)(\pi / 6)\left(\mathrm{D}_{\mathrm{MS}}\right)^{3}(20), \mathrm{N}_{\mathrm{A}}=59 \times 3.14 / 6 \times 203=247013.3$
A). The number of each nano-bound C225 antibody was $\mathrm{A} /\left(\mathrm{B} \times 6.02 \times 10^{23} / \mathrm{N}_{\mathrm{A}}\right)=94.65$.

Cell cytotoxicity of C225-GNPs. As shown in Fig. 2A-C., the cell viability of the three groups decreased with an increasing concentration of drug. There was no significant difference in cell inhibition rate between GNP-treated cells and C225-GNP-treated cells at the same drug concentration $(\mathrm{P}>0.05)$. The $\mathrm{IC}_{50}$ values of $\mathrm{C} 225$, GNPs and C225-GNPs in 


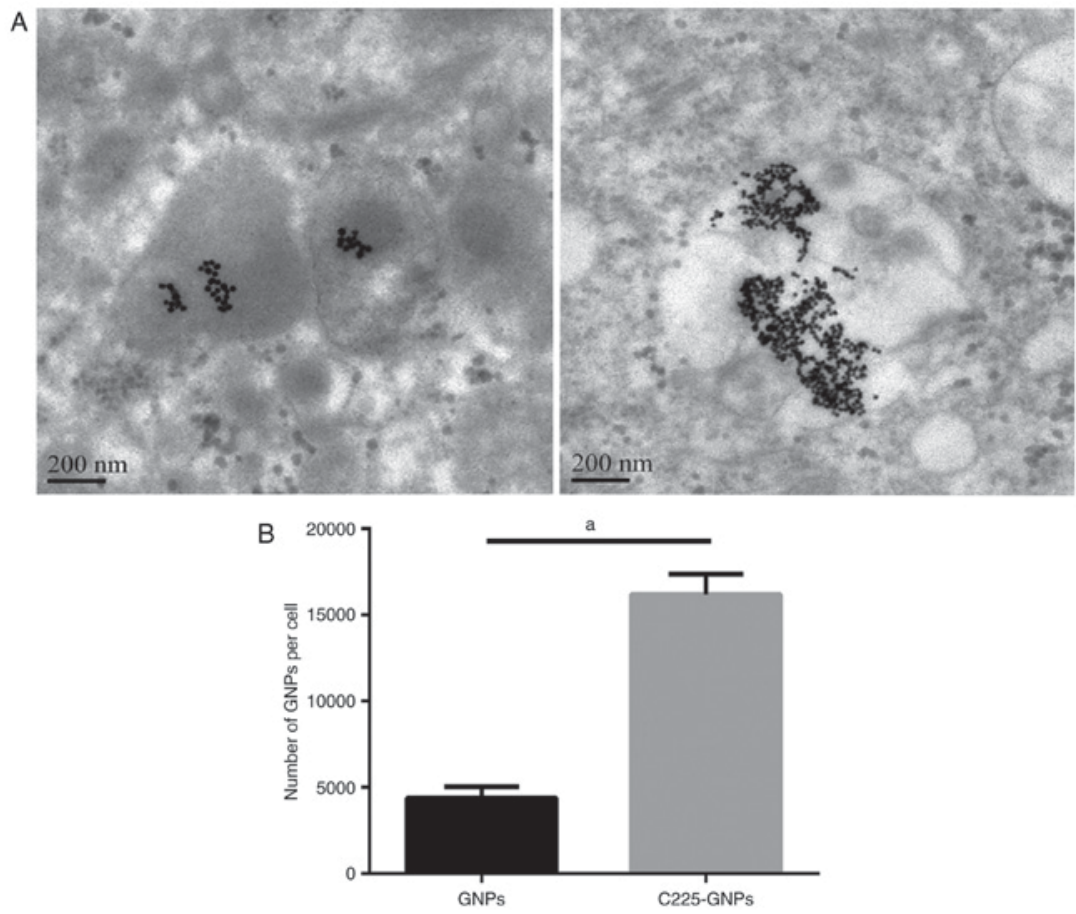

Figure 3. Uptake of GNPs and C225-GNPs in SMCC7721 cells. (A) Images of GNPs (left) and C225-GNPs (right) acquired by transmission electron microscopy. (B) Cellular uptake of GNPs and C225-GNPs into SMCC7721 cells; the number of nanoparticles per single cell is shown. ${ }^{\text {a }}<<0.01$. GNPs, gold nanoparticles; C225, cetuximab.

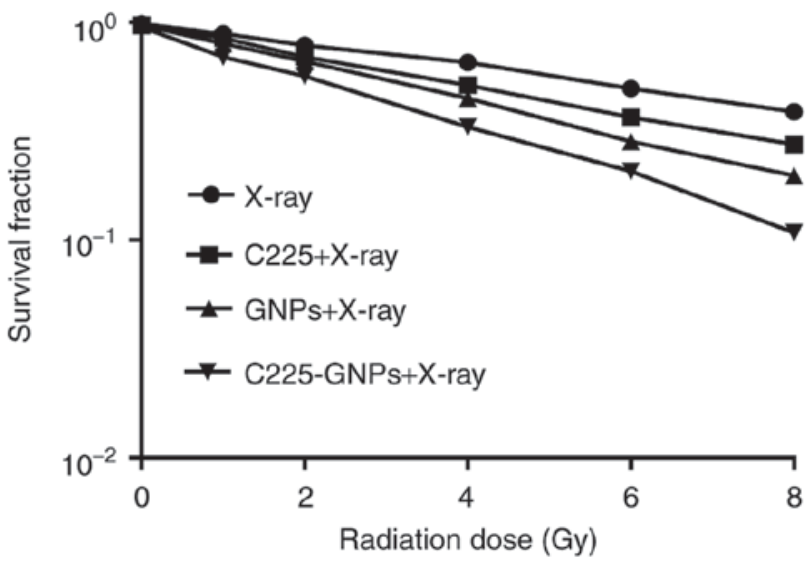

Figure 4. Clonogenic assays demonstrate the radiosensitization effects of C225, GNPs and C225-GNPs on SMCC7721 cells. Exposure to 0-8 Gy of 6-MV X-ray radiation resulted in the dose-dependent clonogenic survival of SMCC7721 cells. The regression curves were fit to a linear-quadratic model. The sensitization enhancement ratios of C225, GNPs and C225-GNPs were $1.35,1.71$ and 2.00, respectively. GNPs, gold nanoparticles; C225, cetuximab.

SMCC7721 cells were 1,404, 6.14 and $4.11 \mu \mathrm{g} / \mathrm{ml}$, respectively. One-fifth of the $\mathrm{IC}_{50}$ value of each drug was used as the experimental concentration in the follow-up assay.

Cell uptake and nanoparticle distribution. To understand the intracellular uptake by human pancreatic cancer cell lines expressing EGFR, SMCC7721 cells were treated with C225-GNPs or with nonspecific isotype control GNPs. Following treatment of the cells with GNPs or C225-GNPs for $24 \mathrm{~h}$, TEM was used to observe the distribution and number of GNPs in cells. The GNPs appeared as dark spots within the cells, and the majority were located around the ER under the
TEM (Fig. 3A). The images further confirmed that the number of C225-GNPs uptaken by the SMCC7721 cells was markedly higher, compared with that of GNPs. FAAS was used to quantitatively determine the quantity of internalised gold in the SMCC7721 cells of the GNP and C225-GNP groups. The quantity of gold was then translated to the number of GNPs per single cell and to the total surface area per single cell. The results showed that more gold was taken up by cells with $\mathrm{C} 225-\mathrm{GNPs}$, whereas the GNPs exhibited poor uptake $(\mathrm{P}<0.01$; Fig. 3B).

Radiosensitivity of SMCC7721 cells to C225-GNPs. The clonogenic cell survival assay was accurately used to determine the enhancement of radiosensitivity by C225, GNPs and C225-GNPs. The survival curves in Fig. 4 show the radiation enhancement effects of the three groups on cell survival fractions combined with different radiation doses of $6 \mathrm{MV}$ X-ray irradiation. There was a significant separation of the curves compared with that of radiation alone $(\mathrm{P}<0.05)$. The curves showed that $\mathrm{C} 225-\mathrm{GNPs}$ induced more radiosensitivity than GNPs, according to the fitting cell survival curve obtained by D0; the SERs of C225, GNPs and C225-GNPs were $1.35,1.71$ and 2.00 , respectively.

Cell apoptosis assay. The annexin V-FITC/AAD double staining procedure was used to calculate the modes of cell death. The percentage of apoptotic cell death, as shown in Fig. 5, is presented as the sum of the percentage of early apoptotic cells and late apoptotic cells. The apoptotic rate in the control group induced by 2 Gy X-ray only was $2.07 \pm 0.42 \%$, and the percentage of apoptotic cells in the C225 and GNP groups, which were exposed to 2 Gy X-ray and drug treated were $5.46 \pm 0.60$ and $6.46 \pm 0.82 \%$, respectively. However, a significant 

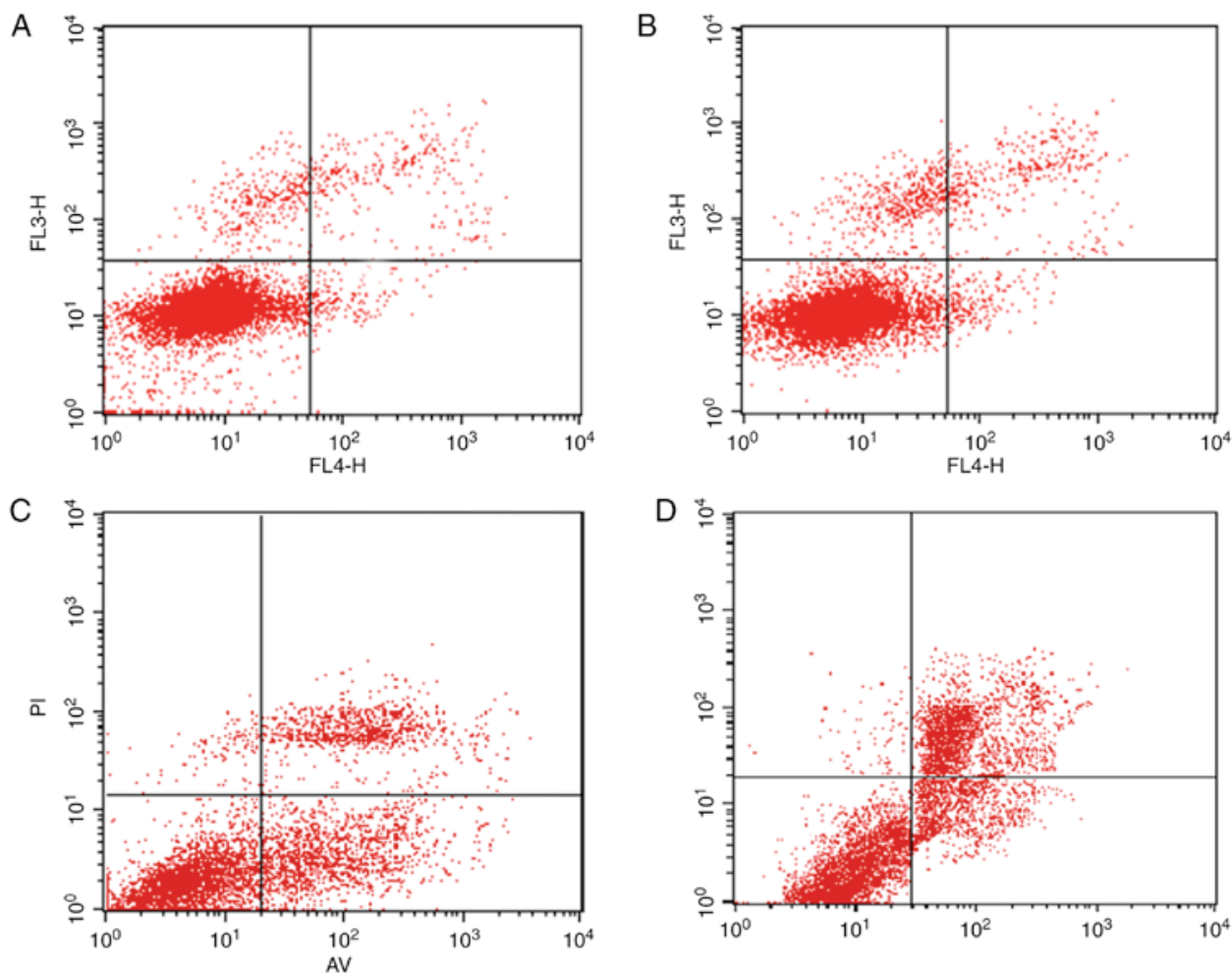

Figure 5. Apoptosis of SMCC7721 cells following treatment with drugs and X-ray was measured by FACS analysis of SMCC7721 cells stained with Annexin V and 7AAD. (A) Control; (B) C225; (C) GNPs; (D) C225-GNPS. Drug concentrations of C225, C225-GNPs and GNPs were one fifth of each 50\% inhibition concentration, and the radiation dose was $2 \mathrm{~Gy}$. The apoptotic rates of the four groups were $2.07 \pm 0.42,5.46 \pm 0.60,6.46 \pm 0.82$ and $13.11 \pm 1.20 \%$, respectively. GNPs, gold nanoparticles; C225, cetuximab.

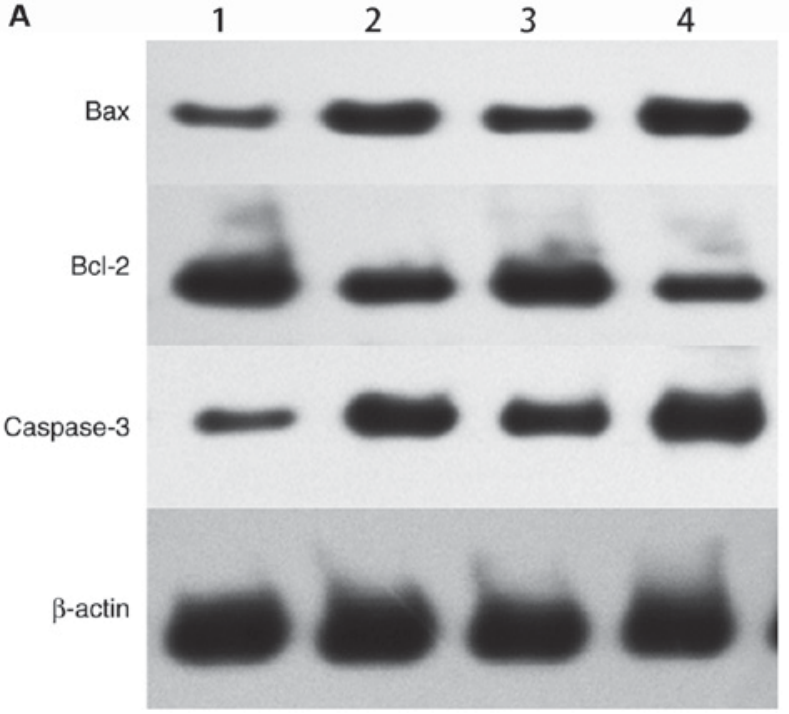

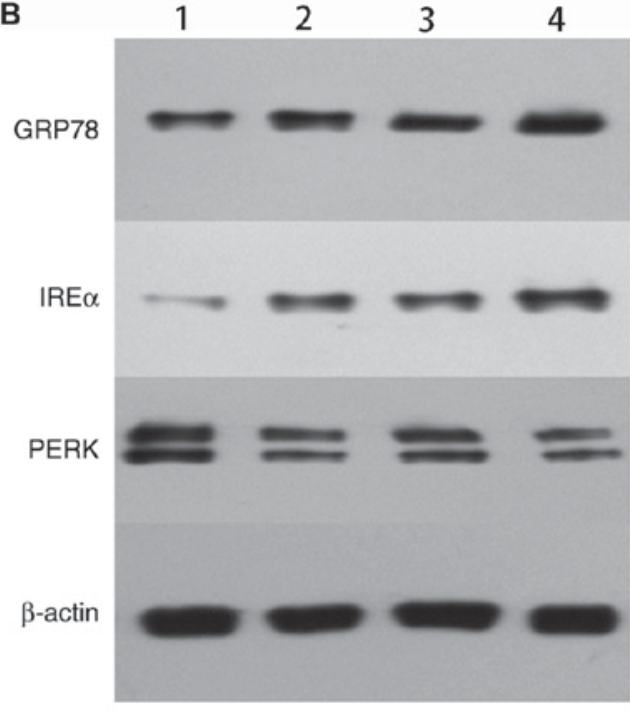

Figure 6. Protein expression levels of Bax, Bcl-2, caspase-3, GRP78, IRE $\alpha$, PERK were detected by western blot analysis. (A) Expression of apoptotic proteins (B) Expression of ERS proteins. 1, X-ray; 2, C225/X-ray; 3, GNPs/X-ray; 4, C225-GNPs/X-ray. Drug concentrations of C225, C225-GNPs and GNPs were one fifth of each 50\% inhibition concentration and the radiation dose was 2 Gy. GNPs, gold nanoparticles; C225, cetuximab; Bcl-2, B-cell lymphoma 2; Bax, Bcl-2-associated X protein; GRP78, glucose-regulated protein 78; IRE1 $\alpha$, inositol-requiring enzyme $\alpha$; PERK, PRKR-like endoplasmic reticulum kinase.

increase in the percentage of apoptosis was detected in the C225-GNP group (13.11 $\pm 1.20 \%)$, compared with that in the C225 and GNP groups, which indicated that the C225-GNPs induced cellular apoptosis more efficiently $(\mathrm{P}<0.05)$.

Western blot analysis. The expression levels of Bax, Bcl-2, and caspase-3 in cells treated with X-ray alone, C225/X-ray,
GNPs/X-ray, or C225-GNPs/X-ray were measured using western blot analysis (Fig. 6A). The expression levels of Bax and caspase- 3 were upregulated, whereas the expression of Bcl-2 was downregulated in cells treated with GNPs/X-ray or C225-GNPs/X-ray. These results indicated that GNPs induced a higher expression of intracellular apoptotic molecules and significantly inhibited the expression of anti-apoptotic 

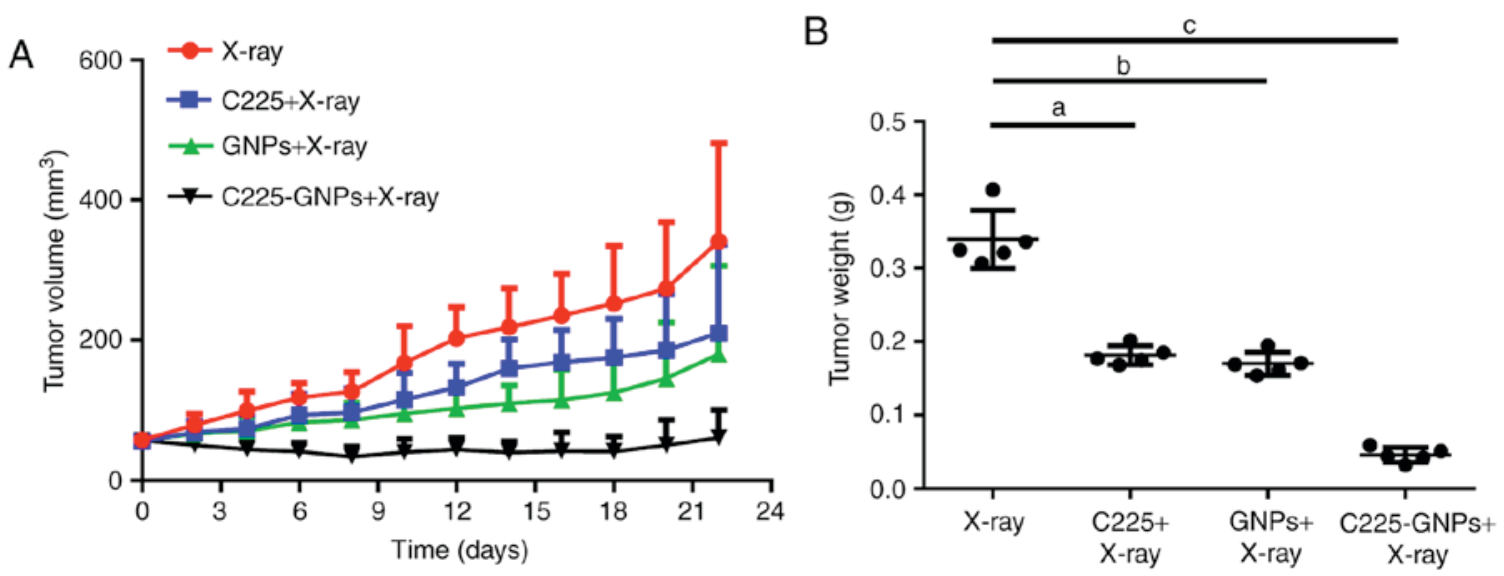

Figure 7. Average changes in tumour volume and tumour weight for each group. (A) Average tumour growth curves (n=5) for mice treated with X-ray, C225, GNPs and C225-GNPs, respectively. (B) Individual tumour weights at termination. ${ }^{\mathrm{a}-\mathrm{C}} \mathrm{P}<0.01$. GNPs, gold nanoparticles; $\mathrm{C} 225$, cetuximab.

proteins, compared with the cells treated with radiation only. The expression of the ERS proteins PERK, GRP78 and IRE $\alpha$, were also measured in the four groups. The results showed that the expression of PERK was downregulated in the cells treated with X-ray alone, C225/X-ray, GNPs/X-ray and C225-GNPs/ $\mathrm{X}$-ray, whereas the expression levels of GRP78 and IRE $\alpha$ were upregulated (Fig. 6B).

In vivo evaluation of the radiosensitization properties of C225-GNPs. The average initial tumour volumes prior to treatment were $57.75 \pm 11.29 \mathrm{~mm}^{3}$ (X-ray only), $56.88 \pm 10.82 \mathrm{~mm}^{3}$ (C225/X-ray), $55.67 \pm 9.91 \mathrm{~mm}^{3}$ (GNPs/X-ray) and $57.44 \pm 8.95 \mathrm{~mm}^{3}$ (C225-GNPs/X-ray). There were no significant differences in these tumour volumes $(\mathrm{P}<0.05)$. Tumour volumes and tumour weights following X-ray and drug treatments are shown in Fig. 7. Following exposure to $20 \mathrm{~Gy} \mathrm{X}$-ray radiation, tumour volumes at experimental termination (day 21) were significantly lower for mice treated with C225-GNPs/ X-ray, compared with X-ray only, C225/X-ray or GNPs/X-ray (Fig. 7A). Furthermore, the use of C225-GNPs/X-ray resulted in significantly slower tumour weight growth, compared with the mice treated with GNPs/X-ray, C225/X-ray or X-ray only $(\mathrm{P}<0.01)$. At the end of the experiment, the tumour weights of mice treated by X-ray only, GNPs/X-ray, C225/X-ray and C225-GNPs/X-ray were $0.339 \pm 0.039,0.181 \pm 0.013,0.17 \pm 0.016$ and $0.046 \pm 0.01 \mathrm{~g}$, respectively (Fig. 7B).

\section{Discussion}

The targeted delivery of nanomaterials is an essential area of investigation for nanomedicine. High atomic number materials, including GNPs, are ideal radiosensitizing agents due to their distinguished absorption of photons and release of secondary energy in the form of X-rays into surrounding tissue. One of the major advantages of GNPs is their formation of stable bonds with various antibodies, peptides and proteins, which allows more GNPs to accumulate in the tumour and leads to further enhancement of the radiation effect on the tumour. The radiosensitivity of targeted-GNPs to tumour cells leading to increased cell death at KV or MV X-ray doses has been realised in various cancer cell lines and animal models $(10,14,16-18)$. However, few reports are available on
HCC with targeted-GNPs regarding radiosensitivity, and the exact radiosensitization mechanism induced by GNPs remains to be elucidated.

The present study aimed to assess the effects of GNP-mediated radiosensitization towards HCC cells in vitro and in vivo, as tumour xenografts in athymic mice. To deliver more GNPs to cancer cells and to specifically radiosensitize them while minimizing side-effects, the present study selected EGFR-overexpressing SMCC7721 cells and EGFR-targeting C225 for delivering GNPs to SMCC7721 cells in vitro and in vivo. When the C225-GNPs conjugates were synthetized, ELISA-based assays were used to quantify the number of C225 antibodies coated per GNP. The results showed there was an average of 94.65 molecules of $\mathrm{C} 225$ bound per GNP. As expected, the cell uptake assay showed that more GNPs conjugates than uncoated GNPs were accumulated in the cancer cell cytoplasm $(\mathrm{P}<0.01)$, suggesting that $\mathrm{C} 225$ significantly increased GNP uptake. The TEM images showed that the majority of the GNPs were distributed in the cytoplasm of cells. This was consistent with a previous report describing the targeting of human pancreatic cancer cell lines with C225-coated GNPs (14). The clonogenic cell survival assay is the gold standard for radiosensitization. The results of the present study showed that the C225, GNPs or C225-GNPs enhanced the radiosensitization of SMCC7721 cells to X-ray, and the SER of the C225-GNP-treated group was the highest due to increased gold uptake by cells. The cell apoptotic rate was also markedly enhanced by C225-GNPs combined with X-ray.

Endothelial network stress (ERS) is a novel pathway of apoptosis, which has been well investigated in previous studies (21-23). It has a cytoprotective function via activating the unfolded protein response (UPR). However, if the cellular damage is too severe or if the stress is excessive, the UPR stimulates the pro-apoptotic cascade and leads to cell death. It is suggested that severe induction of the UPR by overloading the ER capacity enhances cellular sensitivity to radiation or chemotherapeutic agents. The role of the Bcl-2 family in the ERS pathway has been reported in previous years (24). The Bcl-2 family is located in mitochondria but also in the ER and affects its homeostasis. Bcl-2/Bcl-extra large can inhibit ERS-induced apoptosis, and the deletion of Bax and Bcl-2-antagonist/killer 1 can protect ERS-induced apoptosis. 
The ERS-induced activation of caspase-12, which is located in the ER epicardium, activates the caspase- 9 zymogen. The activated caspase- 9 cleaves the caspase- 3 zymogen and eventually leads to the apoptotic cascade.

Cancer cells treated with acriflavine or tunicamycin have been reported to be sensitized to ionizing radiation through activation of the UPR $(25,26)$. In the present study, GNPs accumulated in the cytoplasm and the expression levels of ERS-related proteins GRP78 and IRE $\alpha$ were upregulated. It was also found that the expression of pro-apoptotic proteins Bax and caspase-3 was upregulated, whereas the anti-apoptotic protein $\mathrm{Bcl}-2$ was downregulated in cells. These results suggested that GNPs acted as an ER-inducer and enhanced $\mathrm{X}$-ray-induced apoptosis. These results are supported by findings from previous studies that indicated that GNPs induced ERS and UPR signalling-dependent apoptosis in cancer cells (27). Yasui et al (28), also suggested that GNPs radiosensitized cells by enhancing apoptosis and impairing DNA repair capacity via ERS induction.

Finally, the radiosensitization efficacy of C225-GNPs was demonstrated in vivo in an aggressive orthotopic model of HCC. The in vivo data in the present study clearly indicated that the GNP-based targeted drug delivery system showed the most significant radiation enhancement effect in this xenograft model.

In conclusion, C225-GNP nanoconjugates were successfully synthesized in the present study, and it was shown that the nanoparticles significantly improved the efficacy of radiotherapy in vitro and in vivo, and briefly discussed the mechanism of radiosensitization in SWCC7721 cells. The results suggested that C225-GNPs may be used as a potential radiosensitizer for treating malignant tumours overexpressing EGFR in radiotherapy.

\section{Acknowledgements}

The present study was supported by the Natural Science Foundation of Jiangsu Province (grant no. BK20141084), the General Topics of Nanjing Medical Technology Development Project (grant nos. YKK15141 and YKK15142) and the Key Topics of Nanjing Medical Technology Development Project (grant no. ZKX13019).

\section{References}

1. Siegel RL, Miller KD and Jemal A: Cancer statistics, 2017. CA Cancer J Clin 67: 7-30, 2017.

2. Dhir M, Melin AA, Douaiher J, Lin C, Zhen WK, Hussain SM, Geschwind JF, Doyle MB, Abou-Alfa GK and Are C: A review and update of treatment options and controversies in the management of hepatocellular carcinoma. Ann Surg 263: 1112-1125, 2016.

3. Schlachterman A, Craft WW Jr, Hilgenfeldt E, Mitra A and Cabrera R: Current and future treatments for hepatocellular carcinoma. World J Gastroenterol 21: 8478-8491, 2015.

4. Tanguturi SK, Wo JY, Zhu AX, Dawson LA and Hong TS: Radiation therapy for liver tumors: Ready for inclusion in guidelines? Oncologist 19: 868-879, 2014.

5. Tang WY, Chau SP, Tsang WP, Kong SK and Kwok TT: The role of Raf-1 in radiation resistance of human hepatocellular carcinoma Hep G2 cells. Oncol Rep 12: 1349-1354, 2004.

6. Kim D, Park S, Lee JH, Jeong YY and Jon S: Antibiofouling polymer-coated gold nanoparticles as a contrast agent for in vivo X-ray computed tomography imaging. J Am Chem Soc 129: 7661-7665, 2007.
7. Daniel MC and Astruc D: Gold nanoparticles: Assembly, supramolecular chemistry, quantum-size-related properties, and applications toward biology, catalysis, and nanotechnology. Chem Rev 104: 293-346, 2004.

8. Berrezoug A, Dib ASA and Belbachir AH: Enhanced X-ray absorption by using gold nanoparticles in a biological tissue. Radioprotection 50: 281-285, 2015.

9. Mesbahi A: A review on gold nanoparticles radiosensitization effect in radiation therapy of cancer. Rep Pract Oncol Radiother 15: 176-180, 2010.

10. Zhu CD, Zheng Q, Wang LX, Xu HF, Tong JL,Zhang QA, Wan T and Wu JQ: Synthesis of novel galactose functionalized gold nanoparticles and its radiosensitizing mechanism. J Nanobiotechnol 13: 67, 2015.

11. Yao CP, Zhang LW, Wang J, He Y, Xin J, Wang S, Xu H and Zhang Z: Gold nanoparticle mediated phototherapy for cancer. J Nanomater 2016: Article ID 5497136, 2016.

12. Martinelli E, De Palma R, Orditura M, De Vita F and Ciardiello F: Anti-epidermal growth factor receptor monoclonal antibodies in cancer therapy. Clin Exp Immunol 158: 1-9, 2009.

13. Sogawa $C$, Tsuji AB, Yoshida $C$, Inubushi $M$, Furukawa $T$, Koizumi M, Akahori Y, Ukai Y, Kurosawa G, Kurosawa Y and Saga T: Novel human monoclonal antibody against epidermal growth factor receptor as an imaging probe for hepatocellular carcinoma. Nucl Med Commun 33: 719-725, 2012.

14. Khan JA, Kudgus RA, Szabolcs A, Dutta S, Wang E, Cao S, Curran GL, Shah V, Curley S, Mukhopadhyay D, et al: Designing nanoconjugates to effectively target pancreatic cancer cells in vitro and in vivo. PLoS One 6: e20347, 2011.

15. Dreifuss T, Betzer O, Shilo M, Popovtzer A, Motiei M and Popovtzer R: A challenge for theranostics: Is the optimal particle for therapy also optimal for diagnostics? Nanoscale 7: 15175-15184, 2015.

16. Popovtzer A, Mizrachi A, Motiei M, Bragilovski D, Lubimov L, Levi M, Hilly O, Ben-Aharon I and Popovtzer R: Actively targeted gold nanoparticles as novel radiosensitizer agents: An in vivo head and neck cancer model. Nanoscale 8: 2678-2685, 2016.

17. Day ES, Bickford LR, Slater JH, Riggall NS, Drezek RA and West JL: Antibody-conjugated gold-gold sulfide nanoparticles as multifunctional agents for imaging and therapy of breast cancer. Int J Nanomedicine 5: 445-454, 2010.

18. El-Sayed IH, Huang X and El-Sayed MA: Surface plasmon resonance scattering and absorption of anti-EGFR antibody conjugated gold nanoparticles in cancer diagnostics: Applications in oral cancer. Nano Lett 5: 829-834, 2005.

19. Averitt RD, Westcott SL and Halas NJ: Linear optical properties of gold nanoshells. J Opt Soc Am B 16: 1824-1832, 1999.

20. Alvarez MM, Khoury JT, Schaaff TG, Shafigullin MN, Vezmar I and Whetten RL: Optical absorption spectra of nanocrystal gold molecules. J Phys Chem B 101: 3706-3712, 1997.

21. Ma YJ and Hendershot LM: The role of the unfolded protein response in tumour development: Friend or foe? Nat Rev Cancer 4: 966-977, 2004.

22. Dejeans N, Barroso K, Fernandez-Zapico ME, Samali A and Chevet E: Novel roles of the unfolded protein response in the control of tumor development and aggressiveness. Semin Cancer Biol 33: 67-73, 2015.

23. Galmiche A, Sauzay C, Chevet E and Pluquet O: Role of the unfolded protein response in tumor cell characteristics and cancer outcome. Curr Opin Oncol 29: 41-47, 2017.

24. Kuwana T and Newmeyer DD: Bcl-2-family proteins and the role of mitochondria in apoptosis. Curr Opin Cell Biol 15: 691-699, 2003.

25. Contessa JN, Bhojani MS, Freeze HH, Rehemtulla A and Lawrence TS: Inhibition of N-linked glycosylation disrupts receptor tyrosine kinase signaling in tumor cells. Cancer Res 68: 3803-3809, 2008.

26. Lim MJ, Ahn JY, Han Y, Yu CH, Kim MH, Lee SLO, Lim DS and Song JY: Acriflavine enhances radiosensitivity of colon cancer cells through endoplasmic reticulum stress-mediated apoptosis. Int J Biochem Cell Biol 44: 1214-1222, 2012.

27. Tsai YY, Huang YH, Chao YL, Hu KY, Chin LT, Chou SH, Hour AL, Yao YD, Tu CS, Liang YJ, et al: Identification of the nanogold particle-induced endoplasmic reticulum stress by omic techniques and systems biology analysis. ACS Nano 5: 9354-9369, 2011.

28. Yasui H, Takeuchi R, Nagane M, Meike S, Nakamura Y, Yamamori T, Ikenaka Y, Kon Y, Murotani H, Oishi M, et al: Radiosensitization of tumor cells through endoplasmic reticulum stress induced by PEGylated nanogel containing gold nanoparticles. Cancer Lett 347: 151-158, 2014.

This work is licensed under a Creative Commons Attribution-NonCommercial-NoDerivatives 4.0 International (CC BY-NC-ND 4.0) License. 